\title{
High-Level Resistance to Erythromycin and Tetracycline and Dissemination of Resistance Determinants among Clinical Enterococci in Iran
}

\author{
Nikta Ahmadpoor ${ }^{a}$ Roya Ahmadrajabi ${ }^{b, c}$ Sarvenaz Esfahani ${ }^{b}$ Zoya Hojabrid \\ Mohammad Hassan Moshafi ${ }^{a}$ Fereshteh Saffari ${ }^{\mathrm{c}}$ \\ aDepartment of Pharmacology, School of Pharmacy, Kerman University of Medical Sciences, Kerman, Iran; \\ ${ }^{b}$ Department of Microbiology, School of Medicine, Kerman University of Medical Sciences, Kerman, Iran; \\ 'Medical Mycology and Bacteriology Research Center, Kerman University of Medical Sciences, Kerman, Iran; \\ ${ }^{\mathrm{d}}$ Department of Bacteriology and Virology, School of Medicine, Semnan University of Medical Sciences, Semnan, Iran
}

\section{Highlights of the study}

- Distribution pattern of erm (A-C) was different among enterococci and staphylococci from the same geographic region.

- Alterations at the ribosomal level was more frequently detected in erythromycin and tetracycline resistance than efflux systems.

- Concurrent resistance mechanisms were more involved in resistance to erythromycin than tetracycline.

\section{Keywords}

Enterococcus · Erythromycin · Tetracycline · Antibiotic resistance determinants

\begin{abstract}
Objectives: The purpose of this study was to investigate the distribution pattern of genes responsible for erythromycin and tetracycline resistance and their association with resistance phenotypes in enterococcus isolates. Materials and Methods: Eighty-six Enterococcus faecalis and 26 E. faecium isolates were collected from 2 hospitals in Kerman, Iran. Minimum inhibitory concentration of erythromycin and tetracycline was determined and then genes encoding resistance to erythromycin - erm (A-C), mef, and msr - and tetracycline - tet $(\mathrm{M})$, tet $(\mathrm{O})$, tet $(\mathrm{S})$, tet $(\mathrm{K})$, and tet $(\mathrm{L})$ - were
\end{abstract}

investigated. Results: In all resistant isolates ( $n=72,64 \%$ ), high-level resistance to both tested antibiotics was found. The most prevalent erm gene was erm (B) (77.7\%), followed by erm (A) (15.2\%) and erm (C) (8.3\%). Genes mediating erythromycin efflux were detected in $70.8 \%$ (mef) and $9.7 \%$ ( $m s r)$ of resistant isolates. Regarding tetracycline, tet $(\mathrm{M})$ was detected at the highest rate (50\%), followed by tet (O) $(31 \%)$ and tet (S) (11\%). Export of tetracycline was found in 31\% (tet (K)) and $12 \%$ (tet (L)) of isolates. Conclusion: A high prevalence of high-level resistance to both erythromycin and tetracycline was documented. Alterations at the ribosomal level was more frequently detected in erythromycin and tetracycline resistance than efflux systems. Concurrent resistance mechanisms were more involved in resistance to erythromycin than tetracycline.

(C) 2021 The Author(s)

Published by S. Karger AG, Basel karger@karger.com www.karger.com/mpp

Karger $\stackrel{\text { ' }}{5}$

BOPEN ACCESS
(C) 2021 The Author(s)

Published by S. Karger AG, Basel

This is an Open Access article licensed under the Creative Commons Attribution-NonCommercial-4.0 International License (CC BY-NC) (http://www.karger.com/Services/OpenAccessLicense), applicable to the online version of the article only. Usage and distribution for commercial purposes requires written permission.
Correspondence to:

Mohammad Hassan Moshafi, moshafi14@yahoo.com

Fereshteh Saffari, fsafari@kmu.ac.ir 


\section{Introduction}

Enterococci are considered as important nosocomial pathogens which are resistant to a wide range of antimicrobial agents through intrinsic and acquired mechanisms. Erythromycin and tetracycline are therapeutic agents used for treatment of enterococcal infections. Undoubtedly, the appearance of resistant strains is the result of the extensive use of these antibiotics [1,2]. Methylation of $23 \mathrm{~S}$ rRNA encoded by erm genes which reduces macrolide ability for ribosome binding is one of the most often associated erythromycin resistance mechanisms. Also, export of antibiotics mediated by genes encoding efflux pumps ( $m e f$ and $m s r$ ) is of the other mechanisms involved in macrolide resistance $[3,4]$.

As far as tetracycline resistance is concerned, 2 major mechanisms have been recognized in enterococci. The first, encoded by tet $(\mathrm{M})$, tet $(\mathrm{O})$, and tet $(\mathrm{S})$ confers resistance through ribosomal protection (RP). The second group mediates efflux of tetracycline from cells and is represented by tet $(\mathrm{K})$ and tet $(\mathrm{L})$ genes [5].

In spite of the high frequency of enterococcal infections in our region, studies addressing erythromycin and tetracycline resistance in these organisms are few. The present study tested clinical isolates of enterococci by phenotypic and genotypic means to determine the presence and mechanism(s) of resistance to the mentioned antibiotics.

\section{Methods}

\section{Isolates}

In total, 112 isolates ( $E$. faecalis, $n=86$; E. faecium, $n=26$ ) were collected from 2 hospitals in Kerman, Iran, during 2016-2017. All isolates were considered to be clinically relevant and mostly originated from urine $(n=67)$ and blood $(n=11)$ (Table 1). Species identification was carried out based on biochemical tests and molecular detection of the $d d l$ gene [6].

\section{Susceptibility Testing}

The agar dilution method was performed in Mueller-Hinton agar (Merck, Germany) by the standard methods according to recommendations of the Clinical and Laboratory Standard Institute. E. faecalis ATCCC 29212 was used as the standard strain [7]. The antibiotics tested were erythromycin and tetracycline (Sigma Chemical Co., St. Louis, MO, USA).

\section{PCR Analysis of Resistance Genes}

The presence of genes encoding erythromycin resistance was investigated by amplification of erm genes using specific primers for erm $\mathrm{A}, \mathrm{erm} \mathrm{B}$, and erm $\mathrm{C}$. In addition, the genes involved in the erythromycin efflux system were determined by detection of mef and $m s r$ genes [8]. Duplex PCR assays were performed using 2
Table 1. Distribution of erythromycin- and tetracycline-resistance genes among clinical enterococcus isolates

\begin{tabular}{lclc}
\hline Resistance determinant & $\begin{array}{c}\text { E. faecalis } \\
(n=62)\end{array}$ & $\begin{array}{l}\text { E. faecium } \\
(n=10)\end{array}$ & $\begin{array}{l}\text { Total } \\
(n=72)\end{array}$ \\
\hline erm $\mathrm{B}$ & $51(82.2)$ & $5(50)$ & $56(77.7)$ \\
erm $\mathrm{C}$ & $4(6.4)$ & $2(20)$ & $6(8.3)$ \\
erm $\mathrm{A}$ & $9(14.5)$ & $2(20)$ & $11(15.2)$ \\
$m e f$ & $44(70.9)$ & $7(70)$ & $51(70.8)$ \\
$m s r$ & $6(9.6)$ & $1(10)$ & $7(9.7)$ \\
erm $\mathrm{B}$ and erm $\mathrm{C}$ & $2(3.2)$ & 0 & $2(2.7)$ \\
erm $\mathrm{B}$ and erm $\mathrm{A}$ & $3(4.8)$ & 0 & $3(4.1)$ \\
erm $\mathrm{B}$ and $m s r$ & $4(6.4)$ & 0 & $4(5.5)$ \\
erm $\mathrm{B}$ and $m e f$ & $35(56.4)$ & $3(30)$ & $38(52.7)$ \\
erm $\mathrm{A}$ and $m e f$ & $4(6.4)$ & 0 & $4(5.5)$ \\
erm $\mathrm{C}$ and $m s r$ & $1(1.6)$ & 0 & $1(1.3)$ \\
$m e f$ and $m s r$ & $2(3.2)$ & $1(10)$ & $3(4.1)$ \\
tet $\mathrm{M}$ & $31(50)$ & $5(50)$ & $36(50)$ \\
tet $\mathrm{O}$ & $18(29)$ & $5(50)$ & $23(31)$ \\
tet $\mathrm{S}$ & $5(8)$ & $3(30)$ & $8(11)$ \\
tet $\mathrm{K}$ & $19(30)$ & $4(40)$ & $23(31)$ \\
tet $\mathrm{L}$ & $8(12)$ & $1(10)$ & $9(12)$ \\
tet $\mathrm{M}$ and tet $\mathrm{O}$ & $5(8)$ & $3(30)$ & $8(11.1)$ \\
tet $\mathrm{M}$ and tet $\mathrm{K}$ & $10(16.1)$ & $2(20)$ & $12(16.6)$ \\
tet $\mathrm{M}$ and tet $\mathrm{S}$ & $2(3.2)$ & 0 & $2(2.7)$ \\
tet $\mathrm{K}$ and tet $\mathrm{L}$ & $2(3.2)$ & $1(10)$ & $3(4.1)$ \\
tet $\mathrm{K}$ and tet $\mathrm{O}$ & $1(1.6)$ & $1(10)$ & $2(2.7)$ \\
tet $\mathrm{L}$ and tet $\mathrm{O}$ & $4(6.4)$ & 0 & $4(5.5)$ \\
tet $\mathrm{L}$ and tet $\mathrm{S}$ and tet $\mathrm{K}$ & 0 & $1(10)$ & $1(1.3)$ \\
\hline & & & \\
\hline
\end{tabular}

primer pairs: $m e f / e r m \mathrm{~A}$ and $m s r / e r m \mathrm{C}$. Regarding tetracycline resistance, 5 tet genes using specific primers were investigated including those that confer resistance by RP: tet $(\mathrm{M})$, tet $(\mathrm{O})$, and tet (S) and efflux genes: tet $(\mathrm{K})$ and tet $(\mathrm{L})$ [9]. Multiplex PCR was optimized for multiplex primers of tet $(\mathrm{K}, \mathrm{L}, \mathrm{M}, \mathrm{S})$. PCR amplicons were checked by electrophoresis on $1 \%$ agarose gel. Strains harboring understudied resistance genes, kindly provided by Dr. Kalantar $\mathrm{D}$, were used as positive controls $[10,11]$.

\section{Results}

The majority of studied isolates were resistant to both erythromycin and tetracycline $(n=72,64 \%)$, including $E$. faecalis $(n=62)$ and E. faecium $(n=10)$. All resistant isolates expressed a high level of erythromycin resistance (MIC $>128 \mu \mathrm{g} / \mathrm{mL})$. Regarding tetracycline, all E. faecium and $90 \%$ of E. faecalis $(n=56)$ isolates showed high-level resistance (MIC $>128 \mu \mathrm{g} / \mathrm{mL}$ ), and the remaining ones represented MIC $>64 \mu \mathrm{g} / \mathrm{mL}(n=4)$ and MIC $>32 \mu \mathrm{g} / \mathrm{mL}$ $(n=1)$.

The ermB gene was the most common ( $n=56,77.7 \%)$, followed by mef $(n=51,70.8 \%)$, ermA $(n=11,15 \%), m s r$ 
Table 2. Frequency of enterococcus isolates in terms of the presence of only one resistant mechanism

\begin{tabular}{lclll}
\hline Isolate & $\begin{array}{l}\text { 16SrRNA } \\
\text { methylation }\end{array}$ & $\begin{array}{l}\text { Erythromycin } \\
\text { efflux }^{2}\end{array}$ & $\begin{array}{l}\mathrm{RP} \\
\text { mechanism }^{3}\end{array}$ & $\begin{array}{l}\text { Tetracycline } \\
\text { efflux }^{4}\end{array}$ \\
\hline $\begin{array}{l}\text { E. faecalis }(n=62) \\
\text { E. faecium }(n=10)\end{array}$ & $\begin{array}{c}14(22.5) \\
3(30)\end{array}$ & $\begin{array}{l}5(8) \\
1(10)\end{array}$ & $\begin{array}{c}31(50) \\
4(40)\end{array}$ & $\begin{array}{l}9(14.5) \\
0\end{array}$ \\
\hline Total & $17(23.6)$ & $6(8.3)$ & $35(48.6)$ & $9(12.5)$ \\
\hline
\end{tabular}

RP:ribosomal protection. ${ }^{1}$ Encoded by at least one of the erm (A-C) genes. ${ }^{2}$ Encoded by $m e f$ and/or $m s r .{ }^{3} \mathrm{RP}$ encoded by at least one of the tet $\mathrm{M}$, tet $\mathrm{O}$, or tet $\mathrm{S} .{ }^{4}$ Encoded by tet $\mathrm{K}$ and/or tet $\mathrm{L}$.
( $n=7,9.7 \%)$, and $\operatorname{ermC}(n=6,8.3 \%)$. Comparing two enterococcus species, no significant difference in the distribution of erythromycin resistance determinants was found, although there were some differences between them, as shown in Table 1.

The tet $(\mathrm{M})$ gene was found in half of the studied isolates. Tet $(\mathrm{M})$ was the most prevalent RP gene $(n=36$, $50 \%)$, whereas tet $(\mathrm{S})$ was the least frequent one $(n=8$, $11 \%)$. Among efflux genes, tet $(\mathrm{K})$ was the most dominant gene $(n=23,31 \%)$. All resistant isolates carried at least 1 erythromycin resistance gene, while among tetracyclineresistant isolates, 9 E. faecalis and 1 E. faecium did not harbor any resistance gene.

In total, in $32 \%$ of erythromycin-resistant isolates (23 of 72), one of the resistance mechanisms (erm genes or efflux system) was detected, whereas in 68\% (49 of 72) of them, both mechanisms were involved. Also, the role of erm genes in erythromycin resistance $(23.6 \%, 17 / 72)$ was more common than mef/msr genes $(8.3 \%, 6 / 72)$ (Table 2$)$. Conversely, in $71 \%$ of tetracycline-resistant isolates which contained one of the studied resistance genes (44 of 62), one mechanism and in 29\% (18 of 62), both mechanisms (RP and efflux system) were detected. Similarly, the RP mechanism was more involved in tetracycline resistance than the efflux system ( 48.6 vs. $25 \%$, respectively) (Table 2). No significant difference was found between resistance levels and the presence of one or more resistance genes conferring resistance to a particular antibiotic.

\section{Discussion}

The occurrence of macrolide and tetracycline resistance genes in 2 major enterococcal species was investigated in this study. Erythromycin resistance was more common (64\%) than was previously described in our region or other countries [12-14] but less than that reported in China [1]. Similarly, as reported previously $[1,12,14]$, erythromycin resistance was expressed most often by erm B. Horizontal transfer of erm (B) may be involved which has been shown previously in the isolates from the same clone and even between animals and humans in genetically unrelated isolates [14, 15]. Following erm (B), erm (A) was dominant which is similar to other studies from Iran and China $[1,10]$ but in contrast to a report from Cuba [14]. In the present study, erm $\mathrm{C}$ was detected in $8 \%$ of isolates $(n=6)$. This is in contrast to other reports which did not describe any erm (C) $[12,14]$. Also, the distribution pattern of erm (A-C) genes among enterococci from nonhuman specimens [16-18] was similar to our results. In comparison, the results of this study were in contrast to the situation in Staphylococcus aureus in which erythromycin resistance encoded by erm genes tends to be caused by erm $\mathrm{C}$, followed by erm $\mathrm{A}$ and erm $\mathrm{B}$ [10].

As for genes responsible for erythromycin efflux, the mef gene was the most abundant determinant. This is in contrast to the report from Cuba which did not find any mef gene among enterococcal isolates [14].

The prevalence of tetracycline resistance in our isolates was lower than that reported in studies from Japan and Cuba $[14,19]$ but was higher than that in a report from China [1]. Among tetracycline-resistance genes, tet (M) was the most prevalent, however in less frequencies than other reports from China, Cuba, and Japan $[1,14,19]$. The prevalence of tet $(\mathrm{L})$ in the present study was higher than that reported from China and Cuba, which reported 6.7 and $0 \%$ of tet (L) among E. faecalis isolates, respectively [1, $14]$. Conversely, the prevalence of tet (L) in our study was lower than that reported among E. faecium isolates in Japan [19]. Also, a report from Japan did not find any tet (K) and low frequencies of tet $(\mathrm{O})$ and tet $(\mathrm{S})$; however, in our study, tet $(\mathrm{K})$ and tet $(\mathrm{L})$ were the second most dominant genes, and $11 \%$ of resistant isolates carried the tet $(\mathrm{S})$.

In the present study, some disagreements were observed between the predicted and the actual tetracyclineresistant phenotype. This suggests that other mechanisms 
could be involved in the development of resistance against tetracycline. As expected, 2 studied species showed the same distribution pattern of erythromycin- and tetracycline-resistance genes, and no significant differences were found between these species. This could be due to the fact that our isolates were collected from the same geographic area and at the same time with probably the same antibiotic treatment regimen. Furthermore, no differences were found in the MICs of tetracycline and erythromycin with related resistance genes. One possible explanation is that the actual level of resistance may be dependent on the copy number of resistance gene(s) within the bacterial cell as well as their level of expression. Interestingly, the alteration at the ribosomal level (methylation of 16srRNA and RP) were more involved in erythromycin and tetracycline resistance than did efflux systems. Conversely, in erythromycin-resistant isolates, the presence of both concurrent mechanisms was more evident than tetracycline resistance in which dominant involvement of only one resistance mechanism was observed.

\section{Conclusion}

The high prevalence of high-level resistance to both erythromycin and tetracycline was documented. The distribution pattern of erm (A-C) genes was unexpectedly different between enterococci and staphylococci from the same geographic region. Concurrent resistance mechanisms were more involved in resistance to erythromycin versus tetracycline.

\section{Acknowledgements}

The authors thank the staff at the Department of Microbiology and Virology, Kerman University of Medical Sciences, Kerman, Iran.

\section{Statement of Ethics}

The present study was approved by the Ethics Committee of the Research Council of Kerman University of Medical Sciences, Kerman, Iran (IR.KMU.REC.1397.329).

\section{Conflict of Interest Statement}

The authors declare no conflict of interest.

\section{Funding Sources}

This work was supported by the Research Council of the Kerman University of Medical Sciences, Kerman, Iran.

\section{Author Contributions}

Nikta Ahmadpoor: conceptualization, investigation, and writing of the original draft. Roya Ahmadrajabi: conceptualization, investigation, review, and editing. Sarvenaz Esfahani: investigation and writing of the original draft. Zoya Hojabri: statistical analysis and writing of the original draft. Mohammad Hassan Moshafi: conceptualization, review, and editing. Fereshteh Saffari: conceptualization, writing of the original draft, and supervision.

\section{References}

1 Tian Y, Yu H, Wang Z. Distribution of acquired antibiotic resistance genes among Enterococcus spp. isolated from a hospital in Baotou, China. BMC Res Notes. 2019 Dec;12(1):27.

2 Garrido AM, Gálvez A, Pulido RP. Antimicrobial resistance in enterococci. J Infect Dis Ther. 2014 Jun;2:4

3 Choi J, Rieke EL, Moorman TB, Soupir ML, Allen HK, Smith SD, et al. Practical implications of erythromycin resistance gene diversity on surveillance and monitoring of resistance. FEMS Microbiol Ecol. 2018 Apr; 94(94):1-11.

4 DiPersio LP, DiPersio JR, Frey KC, Beach JA. Prevalence of the erm $(\mathrm{T})$ gene in clinical isolates of erythromycin-resistant group D Streptococcus and Enterococcus. Antimicrob Agents Chemother. 2008 Apr;52(4):1567-9.

5 Huys G, D'Haene K, Collard JM, Swings J. Prevalence and molecular characterization of tetracycline resistance in Enterococcus iso- lates from food. Appl Environ Microbiol. 2004 Mar;70(70):1555-62.

6 Saffari F, Dalfardi MS, Mansouri S, Ahmadrajabi R. Survey for correlation between biofilm formation and virulence determinants in a collection of pathogenic and fecal Enterococcus faecalis isolates. Infect Chemother. 2017 Sep;49(3):176-83.

7 Clinical and Labratory Standard Institute (CLSI). Performance standards for antimicrobial susceptibility testing. 25th informational supplement. Wayne, PA: CLSI; 2015. p. M100-S23.

8 Zou LK, Wang HN, Zeng B, Li JN, Li XT, Zhang AY, et al. Erythromycin resistance and virulence genes in Enterococcus faecalis from swine in China. New Microbiol. 2011 Jan; 34(1):73-80.

9 Rathnayake IU, Hargreaves M, Huygens F. Antibiotic resistance and virulence traits in clinical and environmental Enterococcus fae- calis and Enterococcus faecium isolates. Syst Appl Microbiol. 2012 Jul;35(35):326-33.

10 Fasihi Y, Saffari F, Ghahraman MR, KalantarNeyestanaki D. Molecular detection of macrolide and lincosamide-resistance genes in clinical methicillin-resistant Staphylococcus aureus isolates from Kerman, Iran. Archi Pediatr Infect Dis. 2017 Jan;5(1):1-5.

11 Emaneini M, Bigverdi R, Kalantar D, Soroush S, Jabalameli F, Noorazar Khoshgnab B, et al. Distribution of genes encoding tetracycline resistance and aminoglycoside modifying enzymes in Staphylococcus aureus strains isolated from a burn center. Ann Burns Fire Disasters. 2013 Jun;26(26):76.

12 Emaneini $M$, Aligholi M, Aminshahi M. Characterization of glycopeptides, aminoglycosides and macrolide resistance among Enterococcus faecalis and Enterococcus faecium isolates from hospitals in Tehran. Pol J Microbiol. 2008 Jan;57(2):173-8. 
13 Arabestani MR, Nasaj M, Mousavi SM. Correlation between infective factors and antibiotic resistance in enterococci clinical isolates in west of Iran. Chonnam Med J. 2017 Jan; 53(53):56-63.

14 Quiñones D, Marrero D, Llop A, Kobayashi N, del Campo R. Genetic diversity and antibiotic resistance determinants of Enterococcus faecalis isolates causing pediatric infections in Cuba. J Pediatr Infect Dis. 2009 Jan;4(3):267-74.

15 De Leener E, Martel A, De Graef EM, Top J, Butaye P, Haesebrouck F, et al. Molecular analysis of human, porcine, and poultry En- terococcus faecium isolates and their erm(B) genes. Appl Environ Microbiol. 2005 May; 71(71):2766-70.

16 Aarestrup FM, Agerso Y, Gerner-Smidt P, Madsen M, Jensen LB. Comparison of antimicrobial resistance phenotypes and resistance genes in Enterococcus faecalis and Enterococcus faecium from humans in the community, broilers, and pigs in Denmark. Diagn Microbiol Infect Dis. 2000 Jun;37(2):127-37.

17 Liu Y, Liu K, Lai J, Wu C, Shen J, Wang Y. Prevalence and antimicrobial resistance of Enterococcus species of food animal origin from Beijing and Shandong Province, China. J Appl Microbiol. 2013 Feb;114(114):555-63.

18 Obeng AS, Rickard H, Ndi O, Sexton M, Barton M. Comparison of antimicrobial resistance patterns in enterococci from intensive and free range chickens in Australia. Avian Pathol. 2013 Feb;42(1):45-54.

19 Nishimoto Y, Kobayashi N, Alam MM, Ishino M, Uehara N, Watanabe N. Analysis of the prevalence of tetracycline resistance genes in clinical isolates of Enterococcus faecalis and Enterococcus faecium in a Japanese hospital. Microb Drug Resist. 2005 Jun;11(11):146-53. 